\title{
PENGARUH KUALITAS PELAYANAN ROOMBOY TERHADAP KEPUASAN TAMU MENGINAP DI DAIMA HOTEL PADANG
}

\author{
Annisa Khairani Harahap ${ }^{1}$, Ira Meirina Chair ${ }^{2}$ \\ Program Studi D4 Manajemen Perhotelan \\ Fakultas Pariwisata Dan Perhotelan \\ Univeritas Negeri Padang \\ E-mail : annisaharahap996@gmail.com
}

\begin{abstract}
The purpos of this study is to find out how much influence the service quality of roomboy has on guest satisfaction staying at Daima Hotel Padang. This type of research is quantitative descriptive research. The sampling technique used was incidental technique with 97 people as samples. Data collection techniques are carried out by distributing questionnaires using a Likert scale. The results showed that: (1) Roomboy's Service Quality was in the good category (40.21\%) (2) Guest Satisfaction Staying at Daima Padang Hotel was in the satisfied category (57.73\%), (3) Linear regression hypothesis test results simple obtained $F 17,388$ with the value of sig. 0,000<0,05, with a $R$ square value of 0,155. This means that roomboy service quality variables have an effect of $15.5 \%$ on guest satisfaction deserving at Daima Hotel Padang and $84.5 \%$ influenced by other factors.
\end{abstract}

Key words: Guests Satisfaction, Service Quality, Hotel

\section{PENDAHULUAN}

Seiring dengan pesatnya

perkembangan industri pariwisata di tanah air ini, dimana hal tersebut ditandai dengan banyak bermunculan industri-industri pariwisata di Indonesia serta sadarnya masyarakat yang dimana faktor wisata dan jasa sudah menjadi kebutuhan pada saat ini. Tentunya hal tersebut harus menjadi perhatian bagi pengelola industri pariwisata untuk meningkatkan dan mengembangkan sarana prasarana yang ada.

Menurut Sulastiyono (2007:

3) "Hotel merupakan bagian yang integral dari usaha pariwisata yang dapat dikatakan sebagai suatu usaha akomodasi yang komersial menyediakan fasilitas sebagai berikut: kamar, makanan dan minuman, dan pelayanan penunjang lainnya (tempat rekreasi, sarana olahraga, laundry, meeting room, spa dan lain sebagainya)". Bidang 
pariwisata dan perhotelan dituntut berlomba memperbaiki pelayanan jasanya dengan cara memperhatikan apa yang menjadi kebutuhan dan harapan para konsumen pengguna jasa karena salah satu faktor yang sangat mempengaruhi tingkat keberhasilan atau tercapainya target pariwisata dan perhotelan yang berkembang dan menentukan tingkat kualitas adalah kemampuan perusahaan dalam memberikan pelayanan kepada pelanggan. Semua fasilitas tersebut bertujuan untuk membuat tamu merasa nyaman berada dalam hotel agar terciptanya kepuasan pelanggan/tamu.

\section{Jasa hotel yang ditawarkan}

kepada pelanggan harus berkualitas agar pelanggan merasa senang terhadap jasa yang dirasakannya, kualitas pelayanan karyawan hotel juga harus diperhatikan demi menciptakan kepuasan pelanggan/tamu. Hal ini sejalan dengan pendapat Rangkuti (2003: 30) yang mengatakan bahwa, "Faktor yang mempengaruhi kepuasan pelanggan yaitu tentang kualitas jasa pelayanan, produk, harga dan faktor-faktor yang bersifat pribadi serta bersifat situasi sesaat".

Salah satu faktor penentu kepuasan pelanggan/tamu ialah kualitas pelayanan. Menurut Lewis \& Booms dalam Tjiptono (2012:157), “kualitas jasa/pelayanan ialah ukuran seberapa bagus tingkat layanan yang diberikan sesuai dengan ekspektasi pelanggan”. Parasuraman Zeithaml dan Berry dalam Tjiptono dan Chandra (2011: 198), “Ciri-ciri kualitas juga dapat dievaluasi kedalam lima dimensi besar yaitu bukti langsung (tangibles), empati (emphaty), kehandalan (reliability), daya tanggap (responsiveness) dan jaminan (assurance)".

Kualitas

pelayanan merupakan hal yang paling utama diperhatikan dalam industri jasa hotel karena itu yang menentukan kepuasan tamu/pelanggan. Kualitas pelayanan hotel bisa diwujudkan melalui pemenuhan kebutuhan dan keinginan pelanggan serta ketepatan penyampaiannya untuk mengimbangi harapan pelanggan termasuk pula dengan 
hotel-hotel yang ada di Kota Padang.

Menurut Sulastiyono dalam Chair dan Pramudia (2017: 24) Tata graha (Housekeeping) adalah "Bagian yang bertanggug jawab terhadap hal-hal yang menyangkut kebersihan, kerapian, kelengkapan, keindahan, perawatan dan kesehatan serta kenyamanan diseluruh kamar tamu dan ruangan umum, serta penanganan dan perawatan Guest Laundry dan House Laudry". Salah satu seksi yang ada di Housekeeping Department ialah roomboy/room attendant. Menurut Rumekso (2002) roomboy adalah petugas yang menjaga kebersihan, kerapihan, keindahan, kenyamanan, dan kelengkapan kamar-kamar tamu. Baik buruknya kamar hotel tergantung dari kualitas roomboy hotel tersebut, agar tamu mendapatkan kepuasan maka roomboy harus memberikan pelayanan yang berkualitas, karena pada umumnya penghasilan terbesar pada hotel didapat dari hasil penjualan kamar.

\section{$\max x=$


sampling incidental dengan jumlah sampel 97 orang. Teknik pengumpulan data dilakukan dengan cara penyebaran kuesioner dengan menggunakan skala Likert yang telah teruji validitas dan reliabilitasnya. Selanjutnya data dianalisis dengan uji regresi linear sederhana dan koefisien derminasi menggunakan bantuan program computer SPSS (Statistic Product Solution And Service) versi 20.00.
Hasil Penelitian dan Pembahasa

n

\section{Hasil Penelitian}

a. Analisis Deskriptif

1) Kualitas Pelayanan

Roomboy

Hasil

penelitian pada variabel kualitas pelayanan roomboy dikategori dalam tabel dibawah ini:

Tabel 1. Hasil Deskripsi Data Variabel Kualitas Pelayanan

\section{Roomboy}

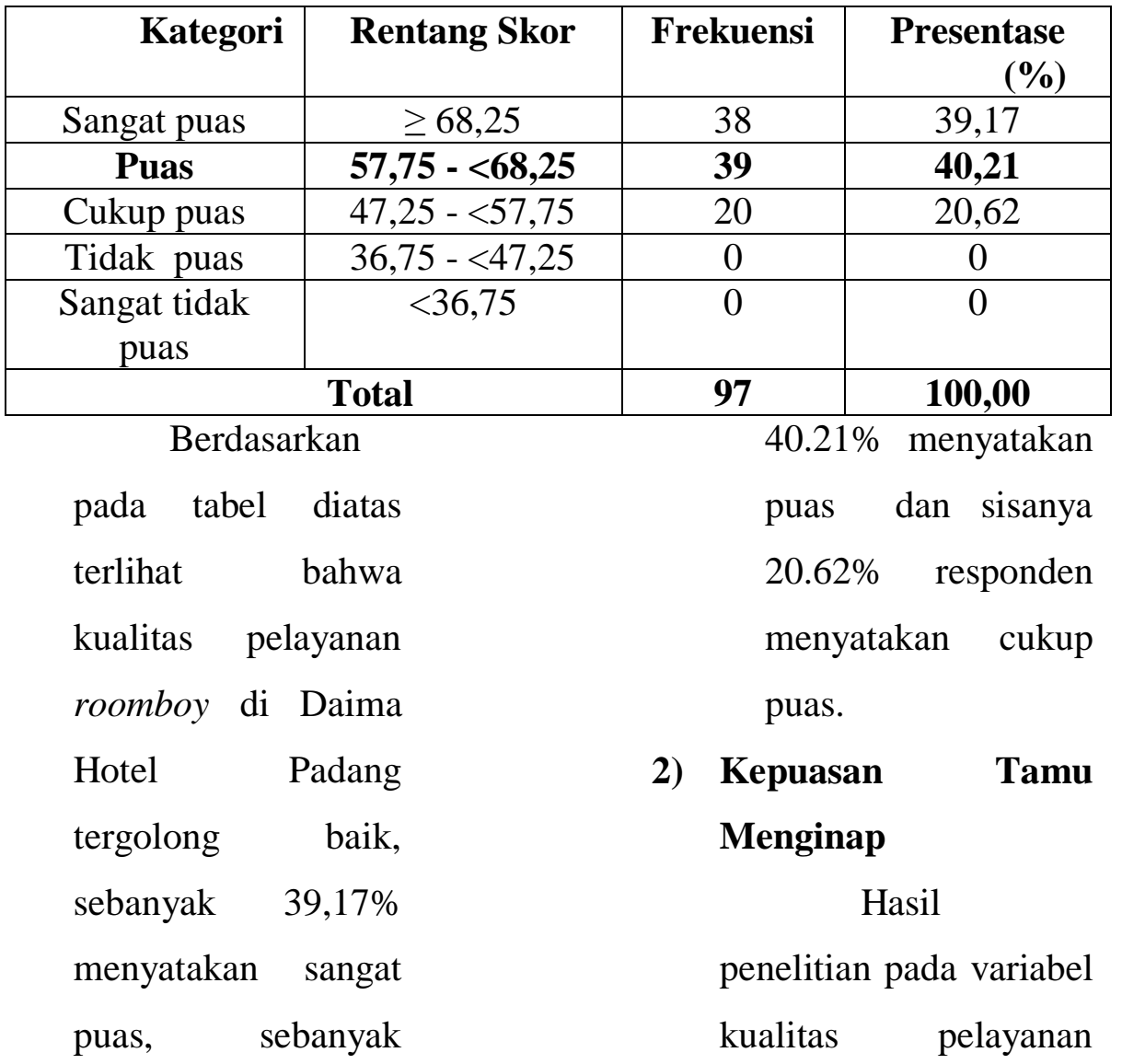


roomboy dikategori

dalam

tabel dibawah ini:

Tabel 2. Hasil Deskripsi Data Variabel Kepuasan Tamu Menginap

\begin{tabular}{|c|c|c|c|}
\hline Kategori & Rentang Skor & Frekuensi & $\begin{array}{c}\text { Presentase } \\
(\%)\end{array}$ \\
\hline Sangat puas & $\geq 45,5$ & 2 & 02,06 \\
\hline Puas & $38,5-<45,5$ & 56 & 57,73 \\
\hline Cukup puas & $31,5-<38,5$ & 39 & 40,21 \\
\hline Tidak puas & $24,5-<31,5$ & 0 & 0 \\
\hline $\begin{array}{l}\text { Sangat tidak } \\
\text { puas }\end{array}$ & $<24,5$ & 0 & 0 \\
\hline & Total & 97 & 100,00 \\
\hline \multicolumn{2}{|c|}{ Berdasarkan } & \multirow{5}{*}{$\begin{array}{l}\text { b. Uji } \\
\text { 1) }\end{array}$} & menyatakan \\
\hline \multicolumn{2}{|c|}{ pada tabel diatas } & & puas. \\
\hline \multicolumn{2}{|c|}{ terlihat bahwa } & & Persyaratan Analisis \\
\hline kepuasan & tamu & & Uji Normalitas \\
\hline menginapc & Daima & & Hasil \\
\hline Hotel & Padang & \multicolumn{2}{|r|}{ normalitas dari variabel } \\
\hline sebanyak & $2,06 \%$ & \multirow{2}{*}{\multicolumn{2}{|c|}{$\begin{array}{l}\text { kualitas pelayanan } \\
\text { roomboy dan kepuasan }\end{array}$}} \\
\hline responden & & & \\
\hline \multicolumn{2}{|c|}{ menyatakan sangat } & \multirow{2}{*}{\multicolumn{2}{|c|}{$\begin{array}{l}\text { tamu menginap dapat } \\
\text { dikategorikan }\end{array}$}} \\
\hline puas, & sebanyak & & \\
\hline \multicolumn{2}{|c|}{$57,73 \%$ menyatakan } & \multicolumn{2}{|r|}{ pada tabel } \\
\hline puas, & $40,21 \%$ & & dibawah ini: \\
\hline
\end{tabular}

Tabel 3. Hasil Uji Normalitas

\begin{tabular}{|c|c|c|}
\hline & $\begin{array}{l}\text { Kualitas } \\
\text { pelayanan } \\
\text { roomboy }\end{array}$ & $\begin{array}{c}\text { Kepuasan } \\
\text { tamu } \\
\text { menginap }\end{array}$ \\
\hline $\begin{array}{l}\text { N } \\
\text { Normal Parameters } \\
\text { a,b } \quad \text { Mean }\end{array}$ & $\begin{array}{r}97 \\
65.41\end{array}$ & $\begin{array}{r}97 \\
39.33\end{array}$ \\
\hline
\end{tabular}




\begin{tabular}{|l|r|r|r|} 
& Std. & 8.415 & 2.668 \\
& Deviation & .123 & .123 \\
Most Extreme & Absolute & .123 & .123 \\
Differences & Positive & -.112 & -.082 \\
Kolmogorov-Smirnov Z Negative & 1.208 & 1.206 \\
\hline & Ksymp. Sig. (2-tailed) & .108 & .109 \\
\hline
\end{tabular}

a. Test distribution is Normal.

b. Calculated from data.

Pada tabel

diatas dapat kita lihat

nilai Kolmogrov-

Smirnov $Z$ variabel

kualitas pelayanan

roomboy adalah 1,208,

variabel kepuasan tamu

adalah 1,206 dan

variabel keputusan

pembelian adalah

sebesar $\quad 1,266$.

Dengan nilai

signifikansi

dari 0,05,

maka dapat dikatakan

bahwa

data tersebut normal.

\section{2) Uji Homogenitas}

Hasil uji

homogenitas dari

variabel kualitas

pelayanan roomboy dan

kepuasan tamu

menginap dapat

dikategorikan pada tabel

dibawah ini:

Tabel

4.

\section{Hasil Uji Homogenitas}

Test of Homogeneity of Variances

kepuasan_tamu

\begin{tabular}{|r|r|r|r|}
\hline $\begin{array}{l}\text { Levene } \\
\text { Statistic }\end{array}$ & \multicolumn{1}{c|}{ df1 } & \multicolumn{1}{c|}{ df2 } & \multicolumn{1}{c|}{ Sig. } \\
\hline .662 & 22 & 70 & .860 \\
\hline
\end{tabular}

Berdasarkan

tabel di atas dapat kita

lihat nilai sig, 0,860

dengan taraf signifikan

si

0,05 , sehingga dapat

diambil kesimpulan

bahwa data berasal

dari populasi yang

mempunyai varians

yang sama atau data

bersifat homogen.

3) Uji Linearitas

Hasil

uji

Linearitas

dari

variabel

kualitas pelayanan 
roomboy

dan kepuasan tamu

menginap dapat

dikategorikan

pada tabel

dibawah ini:

Tabel 5. Uji Linearitas

ANOVA Table

\begin{tabular}{|c|c|c|c|c|c|c|c|}
\hline & & & $\begin{array}{l}\text { Sum of } \\
\text { Squares }\end{array}$ & df & Mean Square & $F$ & Sig. \\
\hline \multirow{5}{*}{$\begin{array}{l}\text { kepuasan_tamu* } \\
\text { kualitas_pelayanan }\end{array}$} & \multirow[t]{3}{*}{ Between Groups } & (Combined) & 273.398 & 26 & 10.515 & 1.795 & .028 \\
\hline & & Linearity & 105.741 & 1 & 105.741 & 18.051 & .000 \\
\hline & & Deviation from Linearity & 167.658 & 25 & 6.706 & 1.145 & .321 \\
\hline & \multicolumn{2}{|l|}{ Within Groups } & 410.045 & 70 & 5.858 & & \\
\hline & \multicolumn{2}{|l|}{ Total } & 683.443 & 96 & & & \\
\hline
\end{tabular}

Pada tabel di

atas diperoleh nilai

Deviation

from

linearitas

sebesar

$0,321>0.05$, yang

artinya terdapat

hubungan linear

secara signifikan

antara variable

kualitas pelayanan

roomboy (X) dan

kepuasan tamu

menginap (Y). c. Pengujian Hipotesis

1) Uji Regresi Linear Sederhana

Uji regresi

linear sederhana

dilakukan untuk

mengetahui seberapa

jauh pengaruh variable

independen terhadap

variabel dependen.

Hasil uji regresi linear

sederhana dapat dilihat

pada tabel berikut:

Tabel 6. Hasil Uji Regresi Linear Sederhana

ANOVA $^{\mathrm{a}}$ 


\begin{tabular}{|ll|r|r|r|r|r|}
\hline & Regression & 105.741 & 1 & 105.741 & 17.388 & $.000^{\circ}$ \\
1 & Residual & 577.703 & 95 & 6.081 & \\
& Total & 683.443 & 96 & & & \\
\end{tabular}

a. Dependent Variable: kepuasan_tamu

b. Predictors: (Constant), kualitas_pelayanan

Berdasarkan

tabel diatas, hasilpuji

regresi linear sederhana

diperoleh nilai $\mathrm{F}$ hitung

adalah 17,388 dengan

tingkat signifikansi

$0,000<0,05$, artinya

variable

kualitas

pelayanan

roomboy

mempengaruhi

kepuasan

tamu diterima dan Ho

ditolak.

Selanjutanya

untuk mengetahui besar koefisien regresi antara variabel kualitas pelayanan roomboy terhadap kepuasan tamu. Maka dapat dilihat pada tabel dibawah ini:

menginap maka $\mathrm{Ha}$

Tabel 7. Koefisien Regresi Variabel X Terhadap Y

Coefficients $^{\mathrm{a}}$

\begin{tabular}{|c|c|c|c|c|c|}
\hline \multirow[t]{2}{*}{ Model } & \multicolumn{2}{|c|}{ Unstandardized Coefficients } & \multirow{2}{*}{$\begin{array}{c}\begin{array}{c}\text { Standardized } \\
\text { Coefficients }\end{array} \\
\text { Beta }\end{array}$} & \multirow[t]{2}{*}{$\mathrm{t}$} & \multirow[t]{2}{*}{ Sig. } \\
\hline & $\mathrm{B}$ & Std. Error & & & \\
\hline (Constant) & 31.171 & 1.972 & & 15.804 & .000 \\
\hline kualitas_pelayanan & .125 & .030 & .393 & 4.170 & .000 \\
\hline
\end{tabular}

a. Dependent Variable: kepuasan_tamu

$$
\mathrm{Y}=\mathbf{a}+\mathbf{b x}=\mathbf{3 1 , 1 7 1 +}
$$

$$
\text { Pada tabel } \mathbf{0 , 1 2 5} \mathbf{x}
$$

diatas didapatkan

Berdasarkan

persamaan regresi

persamaan diatas

sebagai berikut:

diperoleh koefisien 
regresi sebesar 0.125

dengan nilai sig $0,000<$

0,005 artinya setiap

peningkatan sebesar 1

satuan

kualitas

pelayanan

akan

meningkatkan

0.125

satuan kepuasan tamu

menginap.

2) $\mathrm{Uji}$

Koefisien

\section{Determinasi}

Dalam melihat

presentasi besarnya

pengaruh kualitas

pelayanan roomboy

terhadap kepuasan tamu

menginap di hotel

daima padang. Maka

digunakan koefisien

determinasi. Berikut

rangkuman analisis

seperti yang terdapat

pada tabel:

Tabel 8. Hasil analisi korelasional

Model Summary ${ }^{\mathrm{D}}$

\begin{tabular}{|l|r|r|r|r|}
\hline Model & \multicolumn{1}{|c|}{$\mathrm{R}$} & $\mathrm{R}$ Square & \multicolumn{1}{c|}{$\begin{array}{c}\text { Adjusted } \mathrm{R} \\
\text { Square }\end{array}$} & $\begin{array}{c}\text { Std. Error of the } \\
\text { Estimate }\end{array}$ \\
\hline 1 & $.393^{\mathrm{a}}$ & .155 & .146 & 2.466 \\
\hline
\end{tabular}

a. Predictors: (Constant), kualitas_pelayanan

b. Dependent Variable: kepuasan_tamu

Berdasarkan tabel di atas, diperoleh $\mathrm{R}$ Squere 0,155 , yang artinya pengaruh variabel bebas (kualitas pelayanan roomboy) terhadap variabel terikat (kepuasan tamu menginap) adalah sebesar 15,5\%, sedangkan $84,5 \%$ sisanya yang lain dipengaruhi oleh variabel lain seperti, kualitas produk, harga, emosional dan harga yang tidak penulis teliti.

\section{Pembahasan}

Berdasarkan hasil penelitian yang dilakukan, maka dapat dibuat pembahasan tentang kualitas pelayanan roomboy dengan kepuasan tamu menginap serta pengaruh antara kedua variabel tersebut. Dari analisa dapat diketahui bahwa variabel independen (kualitas 
pelayanan roomboy) signifikan

terhadap variabel dependen

(kepuasan tamu menginap).

Penjelasannya adalah sebagai

berikut:

a. Kualitas

Pelayanan

Roomboy ( X )

Berdasarkan hasil

penelitian dapat dijelaskan

bahwa jawaban dari 97 orang

responden tentang variabel

kualitas pelayanan roomboy

di Daima Hotel Padang

tergolong pada kategori baik

dengan persentase $40,21 \%$.

Selanjutnya hasil dari data

per indikator dapat

dikelompokkan sebagai

berikut, 1) Bukti langsung

(tangibles) tergolong pada

kategori baik dengan

persentase 51,54\%, 2) Empati

(emphaty) tergolong pada

kategori baik dengan

persentase $47,42 \%, \quad 3$ )

Kehandalan (reliability)

tergolong pada kategori baik

dengan persentase $47,42 \%, 4$ )

Daya

tanggap

(responsiveness) tergolong pada kategori baik dengan

persentase $\quad 43,30 \%, \quad 5$ )

Jaminan (assurance)

tergolong pada kategori baik dengan persentase $47,43 \%$.

Berdasarkan hasil penelitian tersebut, variabel kualitas pelayanan berada pada kategori baik, walaupun demikian kualitas pelayanan juga harus diperhatikan bahkan lebih ditingkatkan lagi agar dapat mempertahankan kepuasan para tamu menginap.

Menurut Tjiptono (2012:157) mengemukakan ada dua faktor utama yang mempengaruhi kualitas layanan, yaitu layanan yang diharapkan (expected service) dan layanan yang diterima (perceived service). Apabila layanan yang diterima sesuai dengan yang yang diharapkan konsumen, maka kualitas layanan yang bersangkutan akan dinilai baik. Jika layanan yang diterima melebihi layanan yang 
diharapkan, maka kualitas

layanan

dipersepsikan

sebagai kualitas ideal.

Sebaliknya jika layanan yang

diterima lebih jelek dari

layanan yang di harapkan,

maka kualitas layanan

dipersepsikan buruk.

\section{b. Kepuasan Tamu Menginap}

Berdasarkan hasil

penelitian dapat dijelaskan bahwa jawaban dari 97 orang responden tentang variabel kepuasan tamu menginap di Daima Hotel Padang tergolong pada kategori puas dengan persentase $57,73 \%$. Selanjutnya hasil dari data per indikator dapat dikelompokkan sebagai berikut, 1) Tercapainya harapan tamu tergolong pada kategori puas dengan persentase $58,76 \%, 2$ ) Terpenuhinya harapan tamu tergolong pada kategori puas dengan persentase $74,23 \%$, 3) Tercapainya keinginan tamu tergolong pada kategori puas dengan persentase
$69,07 \%, 4)$ Keinginan untuk memakai produk/jasa kembali tergolong pada kategori puas dengan persentase $54,64 \%$, 5) Keinginan untuk merekomendasikan barang dan jasa kepada orang lain tergolong pada kategori puas dengan persentase $62,89 \%$.

Berdasarkan hasil penelitian tersebut, variabel kepuasan tamu menginap berada pada kategori puas, walaupun demikian kepuasan tamu menginap juga harus di perhatikan dan dipertahankan dengan cara meningkatkan kualitas pelayanan agar jangan sampai kepuasan tamu tersebut hanya bersifat sementara saja.

Menurut Permana (2013: 23) "Kepuasan adalah perasaan senang atau kecewa seseorang yang timbul dari membandingkan persepsi tentang kinerja (hasil) dari suatu produk dengan harapan yang dimiliki. Jika kinerja gagal memenuhi harapan 


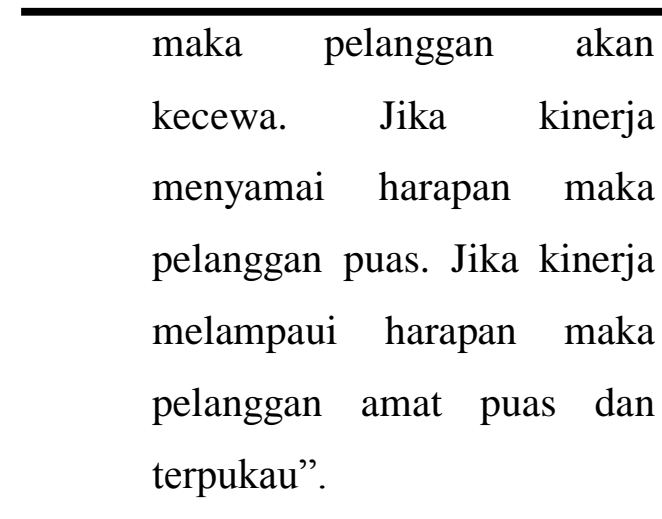

c. Pengaruh

Kualitas

Pelayanan

Roomboy

Terhadap Kepuasan Tamu

Menginap Di Daima Hotel

\section{Padang}

Berdasarkan hasil uji hipotesis yang digunakan untuk mengetahui derajat pengaruh antara kualitas pelayanan roomboy terhadap kepuasan tamu menginap di Daima Hotel Padang. Analisis dilakukan dengan bantuan SPSS 20.00 diperoleh hasil uji regresi linier sederhana diperoleh nilai $\mathrm{F}$ hitung 17.388 dengan sig. $0,000<0,05$ artinya variabel kualitas pelayanan roomboy (X) dapat menjelaskan variabel kepuasan tamu menginap (Y) secara signifikan atau berpengaruh, maka variabel kualitas pelayanan roomboy mempunyai pengaruh secara signifikan terhadap kepuasan tamu menginap. Selanjutnya diperoleh persamaan dengan koefisien regresi sebesar 0,125 dengan nilai sig. 0,000 $<$ 0,05. Artinya setiap peningkatan sebesar 1 satuan kualitas pelayanan roomboy akan meningkatkan 0,125 satuan kepuasan tamu menginap. Kemudian diperoleh nilai koefisien determinasi sebesar 0,155 Artinya pengaruh variabel $\mathrm{X}$ terhadap variabel $\mathrm{Y}$ adalah sebesar $15,5 \%$. Sedangkan $84,5 \%$ dipengaruhi oleh faktor lain seperti kualitas produk, harga, emosional dan biaya.

Kepuasan tamu dilihat dari berbagi aspek salah satu aspek tersebut adalah kualitas pelayanan. Kualitas pelayanan yang baik akan menimbulkan harapan dan keinginan yang baik, 
sehingga apabila pihak hotel

tidak mampu memenuhi harapan tamu maka akan menimbulkan ketidakpuasan yang baik pula. Menurut Lupiyoadi dalam Irawan (2004:37), "Faktor-faktor yang mempengaruhi kepuasan pelanggan adalah kualitas produk, kualitas pelayanan, harga, emosional, dan biaya". Menurut Alma (2009: 169), "Harga merupakan suatu atribut yang melekat pada suatu produk atau jasa dimana produk atau jasa tersebut dapat menjadi faktor yang mempengaruhi kebutuhan, keinginan dan kepuasan tamu yang dinyatakan dengan uang".

Hasil penelitian tersebut dapat disimpulkan bahwa pengaruh kualitas pelayanan terhadap kepuasan tamu di Daima Hotel Padang berpengaruh secara signifikan walaupun ada faktor lain yang dapat mempengaruhi kepuasan tamu seperti kualitas produk, kualitas pelayanan, harga, emosional, dan biaya.

\section{Kesimpulan Dan Saran}

\section{Kesimpulan}

a. Kualitas pelayanan roomboy di Daima Hotel Padang menunjukkan kategori baik dengan nilai presentase $40,21 \%$.

b. Kepuasan tamu menginap di Daima Hotel Padang menunjukkan kategori puas dengan nilai persentase $57,73 \%$.

c. Hasil uji regresi linear sederhana diperoleh nilai $F$ hitung 17,388 dengan nilai sig. $0,000<0,05$ yang artinya variabel $\mathrm{X}$ dapat menjelaskan variabel $\mathrm{Y}$ secara signifikan. Selanjutnya nilai koefisien determinasi sebesar 0,155 . Artinya pengaruh variabel $\mathrm{X}$ terhadap variabel $\mathrm{Y}$ adalah sebesar $\quad 0,155 \quad(15,5 \%)$ sedangkan sisanya $84,5 \%$ dipengaruhi oleh faktor lain. Jadi variabel kualitas pelayanan mempengaruhi 
variabel kepuasan tamu, maka Ha diterima.

\section{Saran}

a. Bagi pihak hotel disarankan untuk lebih meningkatkan kualitas pelayanan roomboy seperti kecepatan dalam melayani tamu, mengerti akan kebutuhan para tamu serta ketanggapan dalam merespon keluhan para tamu. Keramahan karyawan seperti memberi salam dan selalu tersenyum kepada tamu. Walaupun tingkat kualitas pelayanan roomboy di daima hotel padang termasuk kategori baik, alangkah lebih baiknya ditingkatkan menjadi lebih baik lagi demi naiknya citra hotel dan terciptanya tamu yang sangat loyal sehingga juga menguntungkan bagi hotel sendiri.

Pelayanan

merupakan faktor utama para tamu hotel untuk memilih tempat menginap karena pelayanan yang diberikan akan menjadi penilaian bagi responden untuk menginap kembali maupun merekomendasikan hotel kepada orang lain.

b. Diharapkan untuk menyediakan dan melengkapi buku referensi yang ada diperpustakaan sehingga dapat mempermudah mahasiswa dalam mencari referensi penulisan skripsi khususnya mengenai kualitas pelayanan roomboy dan kepuasan tamu menginap.

c. Diharapkan peneliti lebih memperluas kajian tentang faktor yang berhubungan dengan kepuasan pelanggan, karena masih banyak faktor lain seperti: kualitas produk, harga, emosional dan biaya yang memberikan sumbangan yang signifikan terhadap kepuasan pelanggan yang belum terungkap dalam penelitian ini.

\section{DAFTAR PUSTAKA}


Buchari, Alma. 2009. Manajeman

Pemasaran

Dan

Pemasaran Jasa. Cetakan

kedelapan. Bandung:

Alfabeta.

Chair, Ira Merina \& Pramudia,Heru.

2017. Hotel Room

Division Management.

Depok: Kencana.

Diansyah, T. Ira Meirina Chair \& Pramudia, H. (2015). Hubungan Kualitas Pelayanan Karyawan Room Boy dengan Kepuasan Tamu yang Menginap di Hotel Rocky Plaza Padang.EJournal Home Economic and Tourism, 10 (3).

Kurnia, Y. Silfeni \& Ira Meirina Chair, (2017).

HubunganiKualitas

Pelayanan Departemen Front

Office Dengan Kepuasan Tamu Menginap Di Hotel Bumiminang Padang.EJournallHome Economicland Tourism, 15(2).

Lupiyoadi. 2004. Manajemen Pemasaran Jasa Teori dan
Praktek. Salemba Empat Jakarta.

Permana, Agung. 2013. Manajemen Marketing Perhotelan. Yogyakarta: Offset.

Rangkuti, Freddy. 2003. Measuring Customer Satisfaction. Jakarta: PT. Gramedia PustakalUmum.

Rumekso. 2002. Housekeeping Hotel. Yogyakarta: ANDI. Sulastiyono, Agus. 2003. Manajemen penyelenggara Hotel. Bandung: CV Alfabeta.

Tjiptono, Fandy. 2012. Service Management Mewujudkan Layanan Prima.Ed. 2. Yogyakarta: ANDI. 
